\title{
Effect of Sodium Tri Polyphosphate (STPP) and Foreign Materials on the Quality of Giant Freshwater Prawn (Macrobrachium rosenbergii) under Ice Storage Condition
}

\author{
Sujay Paul ${ }^{1}$, Md. Shaheed Reza ${ }^{1 *}$, Abu Saim Mahammed Shadat Mandal' ${ }^{2}$ Imrul Mosaddek Ahmed ${ }^{3}$, \\ Mohammed Nurul Absar Khan ${ }^{1}$, Md. Nazrul Islam', Md. Kamal ${ }^{1}$ \\ ${ }^{1}$ Department of Fisheries Technology, Faculty of Fisheries, Bangladesh Agricultural University, Mymensingh, Bangladesh; ${ }^{2}$ The \\ World Fish Center, Bangladesh and South-Asia Office, Dhaka, Bangladesh; ${ }^{3}$ Bangladesh Agricultural Research Institute, Gazipur, \\ Bangladesh. \\ Email: *rezams@gmail.com,msreza@bau.edu.bd
}

Received May 23 $3^{\text {rd }}$, 2011; revised November 22 $2^{\text {nd }}$, 2011; accepted November $30^{\text {th }}$, 2011

\begin{abstract}
There are reports on the use of chemicals like sodium tri polyphosphate (STPP) and foreign materials like pearl tapioca (locally called 'sagu'), jelly (litchi) to adulterate freshwater prawn (Macrobrachium rosenbergii) prior to freeze processing to increase their weight. Studies were, therefore, undertaken to determine the changes in product quality on the use of different concentrations of STPP, sagu and litchi under ice storage condition. Percent weight gain of prawn was $5.46,18.87$ and 23.50 when dipped in $2 \%, 4 \%$ and $6 \%$ STPP solution, respectively. In all cases maximum water uptake by prawn muscle was during the first $6 \mathrm{~h}$ with fastest weight gain with STPP solutions containing tap water compared to those of ice and tap water. Organoleptic quality of the STPP treated samples became brown and spongy after $8 \mathrm{~h}$ of dipping treatment under iced condition. Quality assessment studies conducted after injecting sagu and litchi in prawn muscle showed little or no difference with those of control samples during the first $6 \mathrm{~h}$, which turned whitish and swollen with severe drip loss after $24 \mathrm{~h}$ of ice stored condition, indicating characteristics for easy identification of the injected shrimps by organoleptic method.
\end{abstract}

Keywords: Adulteration; Freshwater Prawn; Macrobrachium rosenbergii; Pearl Tapioca; Quality Assessment; Sodium Tri Polyphosphate; STPP

\section{Introduction}

Giant freshwater prawn (Macrobrachium rosenbergii de Man) is considered a delicacy by the Asian, European and American populations. It has been widely accepted that this species has characteristic taste, flavor and other sensory characteristics different than other seafood products, and therefore, has become a growing industry in many Asian countries including China, India, Vietnam, Thailand, Bangladesh and even in the United States. In Bangladesh, shrimp and prawn industry is by far the most expanding sector among the agro-based products including tea, raw jute, vegetables, fruits etc. The frozen food industries earned the second largest export sector which reported a total of export earning of US $\$ 556.70$ million in 2009-2010 financial year [1]. It has been reported that these exportable products are sometimes adulterated with different types of chemicals like sodium tri polyphosphate (STPP) and plant starch like pearl

*Corresponding author. tapioca (locally called sagu), barley and gel (litchi) to increase their weight (Kamal 2009: personal communication). In many cases, foreign materials added in shrimp are not detectable as it is injected deliberately into the shrimp body prior to freeze processing. These foreign materials may be directly related to the decomposition and deterioration of the finished products. Due to these low grade products Bangladesh export trade sometimes suffered heavy losses in the form of detention or rejection of a part or full consignment of frozen shrimp, the cancellation of contact or low price offered by importing countries [2]. There is increased pressure from importing countries for fish processors to establish effective quality assurance systems in their plants. There are a number of Council Directives and legislation set for importing the fishery products from developing countries for access to the European market. Bangladesh government also emphasized two issues: 1) Quality and safety (bacteriological quality, contaminants, residues, additives and traceability) and 2) trade issues (labeling, documentation). 
Two Directives bear special relevance to the trade in fishery products.

STPP, with formula $\mathrm{Na}_{5} \mathrm{P}_{3} \mathrm{O}_{10}$ is the sodium salt of triphosphoric acid. It is used in various applications such as a preservative for sea foods, meats, poultry feed and other foods. Phosphates ability to stabilize proteins against denaturation, increase of water binding capacity, improve emulsification and buffering capacity (acidbase relationships), contribute nutrients, chelate metal ions and function as antioxidants are among their contributions to a variety of foods and food products. Protein reactions and water binding are perhaps the most important reasons for the usage of phosphates in seafood. Phosphates are effective on fish and shellfish in preventing drip loss when frozen products are thawed and in enhancing tenderness by restricting protein denaturation during freezing and frozen storage [3]. The use of phosphate has been a "well known secret" in the seafood industry. The United States Food and Drug Administration lists STPP as "generally recognized as safe", along with salt and vinegar. It was reported that a light treatment (0.5 min in 4\% STPP sol.) markedly improved water retention and textural properties of fish muscle [4]. In shrimp processing these additives are used by tumbling the products to bind water. But some industries reported that STPP concentration and tumbling time of the products are directly related to the quality of the products [5]. Consequently, there are reports that the foreign materials incorporated into the shrimp body cause loss of quality of the product with the storage period. So it is very important to know the effect of foreign materials on the quality of shrimp and prawn.

The paper reports the effect of STPP and two foreign materials viz, pearl tapioca (locally called "sagu") and jelly (litchi) on the quality and storage life of prawn by determining organoleptic aspects.

\section{Materials and Methods}

\subsection{Raw Material}

Live freshwater prawn (average weight $15 \pm 0.5 \mathrm{~g}$ ) were collected from a farm of Phulpur in Mymensingh district, Bangladesh and transported to the Department of Fisheries Technology, Bangladesh Agricultural University, Mymensingh in iced condition (1:1 w/w) in an insulated box. These samples were divided into two groups: 72 samples used for STPP treatment and 9 samples for injecting sagu and litchi to evaluate quality.

\subsection{Effect of STPP on the Quality of Shrimp}

Three solutions, $2 \%, 4 \%$ and $6 \%$ STPP was prepared in three separate beakers using mixture of ice and tap water in one lot and three solutions of $2 \%, 4 \%$ and $6 \%$ STPP were prepared using tap water at room temperature in another lot. The samples with head-on, headless, peeled un-deveined (PUD) and peeled deveined (PD) in triplicate were marked using tags and weighted separately in an electric balance. These samples were dipped in each solution for 2 - $8 \mathrm{~h}$. Samples were taken out after definite time intervals and excess water in shrimp body was removed using tissue paper. The samples were weighted again and weight gain was recorded. At the same time, the changes in organoleptic characteristics such as odor, texture, color (with shell), color of flesh and general appearance were monitored for $24 \mathrm{~h}$ according to ECC freshness grade for fishery products with slight modifications [6].

\subsection{Effect of Injecting of Foreign Materials on the Quality of Shrimp}

Nine prawns were used for assessment of quality after injecting of foreign materials using syringes. Prawns were killed in ice and two different treatments were used: 1) prawns injected with pearl tapioca, locally called sagu; 2) prawns injected with jelly like substances locally called litchi. After injecting, the individual sample was weighted and the result of weight gain was calculated compared with control. Quality changes in iced condition was evaluated after taking samples every $8 \mathrm{~h}$ and continued for 1 day according to the method mentioned above.

\subsection{Statistical Analysis}

Data from different measurements were subjected to t-test $(p<0.05)$. The statistical analysis package Statview 5.0 for Macintosh (SAS Institute Inc., NC, USA) was used to explore the statistical significance of the results obtained.

\section{Results and Discussion}

\subsection{Effect of STPP on the Quality of Prawn}

Figures 1 shows the effect of dipping of head-on (A), head-less (B), peeled un-deveined (C) and peeled deveined (D) Macrobrachium rosenbergii in mixture of ice and/or tap water containing different concentrations of STPP. Samples were allowed to dip in 2\% STPP solution for 2 - $8 \mathrm{~h}$. The uptake of water by shrimp muscle increased almost linearly with the increase of dipping time during first $4 \mathrm{~h}$. At that time, the resultant weight gain due to uptake of water was $1.91 \%$ which increased continuously to $2.50 \%$ in $6 \mathrm{~h}$ (Figure 1(a)). The intensity of gaining weight gradually declined with the increase of dipping time. In other dip treatments in mixture of ice and tap water containing $4 \%$ and $6 \%$ STPP solutions, the weight gain increased as a result of uptake of water by shrimp muscle with the increasing of STPP concentra- 
tions during the first $6 \mathrm{~h}$. At the end of $6 \mathrm{~h}$ of dipping, the weight gain of the sample was $4.18 \%$ and $5.57 \%$ for the samples allowed dipping at $4 \%$ and $6 \%$ STPP solutions, respectively, but in all cases, weight gain decreased considerably after $8 \mathrm{~h}$ of dipping (Figure 1(a)). Figure 1(b) shows the dipping of headless $M$. rosenbergii under similar storage conditions. The increasing weight gain with the increasing of storage period in all treatments was more or less similar to that of head-on condition, but uptake of water by prawn muscle was higher than that of head-on condition. Studies conducted using peeled deveined condition showed more or less similar results to those obtained in headless condition

Studies were also conducted on the effect of dipping of $M$. rosenbergii in tap water (without ice) under similar concentrations of STPP to evaluate the any difference in uptake of water by the prawn muscle. The weight gain in tap water in all treatments was significantly higher $(p<$ 0.01 ) then those of samples dipped in mixture of ice and tap water containing different concentration of STPP solutions. The reason of higher weight gain in tap water

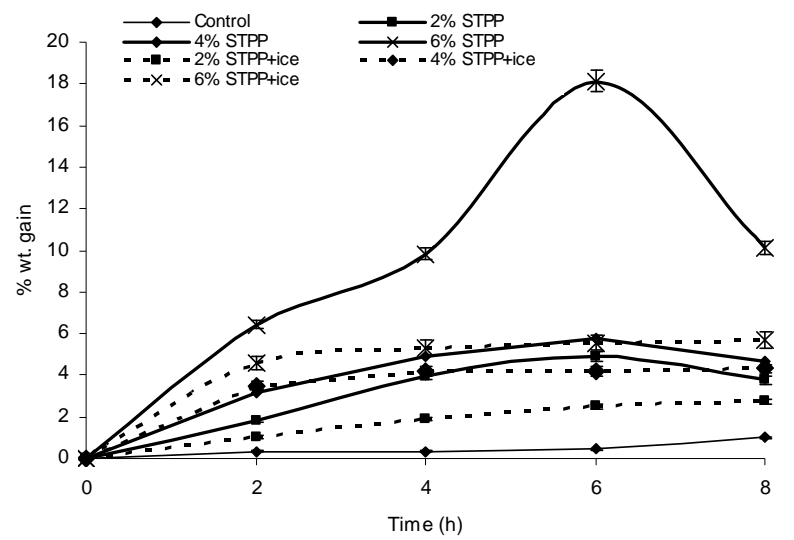

(a)

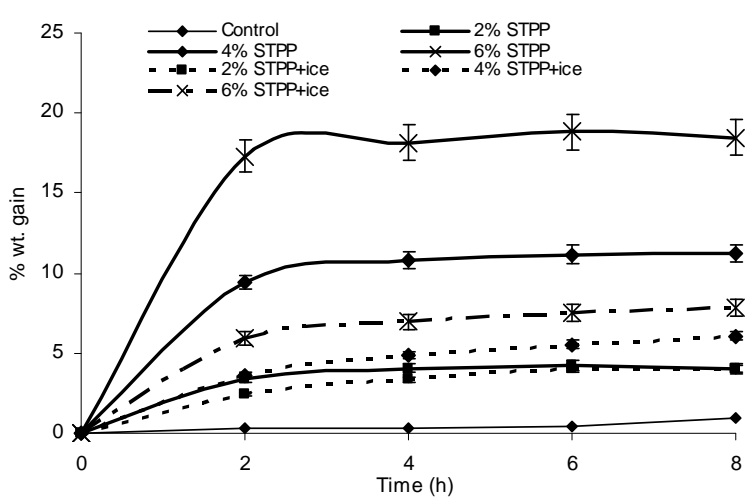

(c) was probably related to the temperature of solutions where the uptake of water by prawn muscle was higher with the higher temperature of STPP solution. It is likely that the temperature of tap water containing different concentration of STPP solutions without ice will be higher than the mixture of ice and tap water containing same STPP solutions (Figure 1(a)-(d)). The reason of increased weight gain in headless and peeled shrimp compared to that of head-on condition is due to prevention in up taking of water by shrimp shell and head. On the other hand, in headless and peeled condition, the muscles are exposed in solutions. Therefore, it is likely to expect that the increased weight gain in peeled and headless shrimp is due to result of higher exposure of muscles in STPP solution.

Studies were also conducted to evaluate the organoleptic quality changes in shrimp after dipping in different concentrations of STPP solutions (Table 1). The degree of freshness of the shrimp having treated with 2\% STPP was higher than those treated in higher STPP concentrations in tap water containing mixture of ice (Table 2). In $2 \%$ STPP solution, organoleptically the samples in mix-

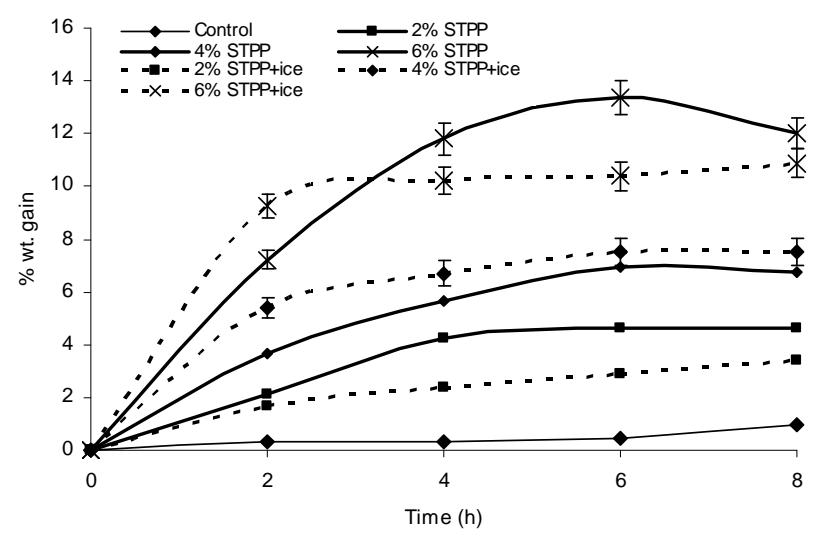

(b)

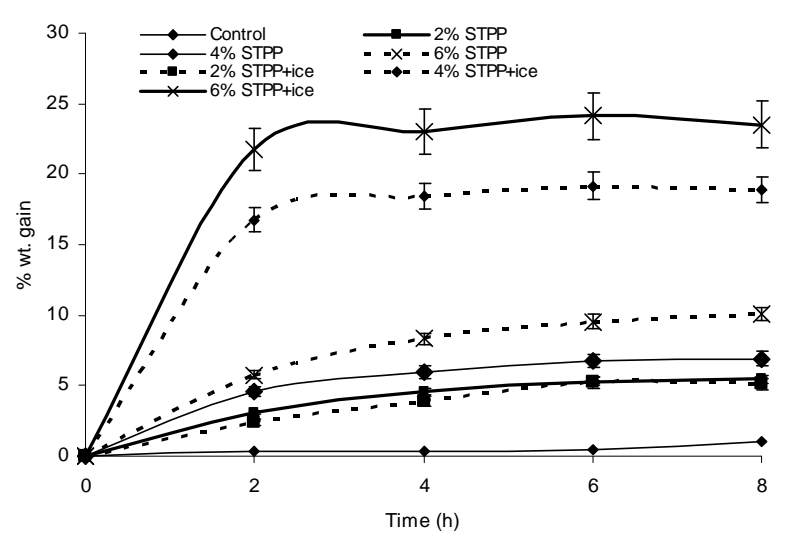

(d)

Figure 1. Effect of STPP on the quality of prawn: Figure 1 shows the effect of dipping of head-on (a); Head-less (b); Peeled un-deveined (c); and peeled deveined (d) Macrobrachium rosenbergii in mixture of ice and/or tap water containing different concentrations of STPP. Figure 1(b) shows the dipping of headless $M$. rosenbergii under similar storage conditions. 
Effect of Sodium Tri Polyphosphate (STPP) and Foreign Materials on the Quality of Giant Freshwater

Prawn (Macrobrachium rosenbergii) under Ice Storage Condition

Table 1. Determination of the grade points of defect.

\begin{tabular}{|c|c|c|}
\hline Characteristics of whole prawn & Defect characteristics & Defect points \\
\hline \multirow{5}{*}{ A. Odor } & Natural odor & 5 \\
\hline & Neutral odor & 4 \\
\hline & Slight sour odor & 3 \\
\hline & Ammonical odor & 2 \\
\hline & Rotted odor & 1 \\
\hline \multirow{4}{*}{ B. Color (With shell) } & Natural odor & 5 \\
\hline & Slight discolor/ Slight pinkish & 4 \\
\hline & Brownish red & 3 \\
\hline & Discolor & 1 \\
\hline \multirow{4}{*}{ C. Color of flesh } & White color of fresh prawn & 5 \\
\hline & Slight pink color & 4 \\
\hline & Pink color & 3 \\
\hline & Dull / discolor & 1 \\
\hline \multirow{5}{*}{ D. Texture } & Firm consistent and elastic & 5 \\
\hline & Moderately soft and some loss of elasticity & 4 \\
\hline & Some softening & 3 \\
\hline & Soft and watery & 2 \\
\hline & Flesh with juice & 1 \\
\hline \multirow{4}{*}{ E. General appearance } & Bright shining and iridescent & 5 \\
\hline & Slight dullness and loss of brightness & 4 \\
\hline & Definite dullness and loss of brightness & 2 \\
\hline & Dull & 1 \\
\hline
\end{tabular}

Table 2. Organoleptic changes of Macrobrachium rosenbergii while dipping in mixture of ice and tap water containing sodium tri polyphosphate (STPP) solutions.

\begin{tabular}{|c|c|c|c|c|c|c|}
\hline \multirow{2}{*}{ Time (h) } & \multicolumn{6}{|c|}{ Defect point } \\
\hline & $2 \%$ STPP + ice & $4 \%$ STPP + ice & $6 \%$ STPP + ice & $2 \%$ STPP without ice & $4 \%$ STPP without ice & $6 \%$ STPP without ice \\
\hline 0 & 25 & 25 & 25 & 25 & 25 & 25 \\
\hline 2 & 22 & 22 & 22 & 22 & 22 & 22 \\
\hline 4 & 22 & 22 & 22 & 22 & 20 & 20 \\
\hline 6 & 22 & 22 & 20 & 20 & 17 & 17 \\
\hline 8 & 22 & 20 & 20 & 17 & 13 & 13 \\
\hline 12 & 20 & 20 & 17 & 17 & 13 & 13 \\
\hline 16 & 17 & 17 & 13 & 13 & 11 & 10 \\
\hline 24 & 15 & 13 & 10 & 13 & 10 & 8 \\
\hline
\end{tabular}

*Degree of freshness: 22 - 25 = excellent; 19 - 21 = good; 14 - 18 = acceptable; 8 - 13 = bad and 5 - 7 = very bad. 
ture of ice and tap water were in excellent/very good condition up to $8 \mathrm{~h}$. At that time, the samples had neutral odour and natural color. The texture was moderately soft and some loss of elasticity. The appearance became slight dull and there was loss of brightness. The samples were in good conditions up to $12 \mathrm{~h}$ when there was some loss of neutral odor with slight discolouration and the flesh became slightly pink. The texture became moderately soft with definite dullness and loss of brightness. However, samples were found in acceptable condition even after 24 h. At that time, slight sour odour was emitting with slight discoloration. The flesh became pink color and there was considerable loss of elasticity in texture with definite dullness and loss of brightness. However, the quality degraded when the samples were dipped in $4 \%$ and $6 \%$ STPP solutions (Table 2). The samples were in good conditions up to $12 \mathrm{~h}$ and acceptable up to $16 \mathrm{~h}$ on the basis of organoleptic characteristics and overall appearance. On the other hand, in 6\% STPP solution the samples were very good to excellent condition up to $4 \mathrm{~h}$, acceptable conditions up to $12 \mathrm{~h}$ and rejected after $16 \mathrm{~h}$ (Table 2).

Studies were also conducted on the quality changes in Macrobrachium rosenbergii in tap water without ice containing different concentration of STPP. On the basis of organoleptic characteristics the samples were in excellent conditions for $4 \mathrm{~h}$ in 2\% STPP solution, $2 \mathrm{~h}$ in $4 \%$ and $6 \%$ STPP solution. The samples in 2\% STPP solution were in good condition up to $6 \mathrm{~h}$ and acceptable up to $12 \mathrm{~h}$. The samples were rejected after $16 \mathrm{~h}$ of dipping. Similarly in $4 \%$ and $6 \%$ STP solutions, the samples were rejected after 8 h of dipping in $4 \%$ and $6 \%$ STPP solutions (Table 2). The study revealed that at higher temperature the quality changes of shrimp in STPP solutions was significantly rapid compared to those dipped in the same solution at lower temperature. The most important organoleptic characteristic change due to addition of STPP during dipping was the appearance of brown color of flesh, stickiness, cohesiveness and swelling of the muscle.

The results of the present study is more or less in agreement with Tenhat et al. [7] and Goncalves and Ribeiro [8] where they reported that the use of STPP diminish the drip loss with increasing moisture content after immersion and some changes occurred in texture where the muscle became more stickiness and springy. The use of STPP is suitable for weight gain and improving the grading of the product and it is useful particularly for producing the value added cooked products where STPP helps to achieve the desired color of the products.

\subsection{Effect of Injecting Foreign Materials on the Quality of Prawn}

Studies were conducted on the quality changes in $M$. rosenbergii after injecting starch materials locally called sagu and jelly like substances locally called litchi. When injecting $5 \mathrm{ml}$ of sagu, there were some changes in organoleptic characteristics. The changes include whitening of the shell and muscle, swelling initially with hard texture and some loss of brightness. At the end of $24 \mathrm{~h}$ of ice storage, there was loss of drip in samples with slight color changes and whitening of muscles (Table 3). With the injection of litchi initial changes were: browning of carapace, initial swelling, irregular shape and subsequent drip loss during ice storage.

There is no report available on the quality changes in shrimp after injecting foreign materials. However, the results obtained from the present study revealed that the adulteration by injecting sagu and litchi by different stakeholders in the shrimp value chain in Bangladesh for illegally increasing weight can easily be identified by carefully monitoring the organoleptic characteristics.

\section{Conclusion}

Assurance of good quality shrimp product as per HACCP rules is a great challenge in Bangladesh. HACCP rules suggested that the shrimp quality preservation start right form the farm and go through all subsequent stages up to the processing factory. So, shrimp farmers, depot owners, transporters and industry owners all have the responsibilities to preserve shrimp from losing its quality and concomitant value. Over use of STPP and longer dipping time of products in STPP solutions have a negative impact on the shrimp products. On the other hand, injecting of sagu and litchi in shrimp body deteriorate the quality

Table 3. Organoleptic changes of Macrobrachium rosenbergii while injecting jelly solution during ice storage.

\begin{tabular}{ccc}
\hline \multirow{2}{*}{ Time (h) } & \multicolumn{2}{c}{ Defect point } \\
\cline { 2 - 3 } & Injecting sagu & Injecting litchi \\
\hline 0 & 25 & 25 \\
2 & 22 & 22 \\
4 & 22 & 22 \\
6 & 22 & 22 \\
8 & 22 & 22 \\
12 & 21 & 21 \\
16 & 20 & 19 \\
24 & 16 & 16 \\
\hline
\end{tabular}

*Degree of freshness: 22 - 25 = excellent; 19 - 21 = good; 14 - 18 = acceptable; 8 - 13 = bad and 5 - 7 = very bad. 
of the shrimp products quickly.

\section{REFERENCES}

[1] DoF, “Saranika, Matsha Soptah-2011,” Directorate of Fisheries, the Government of Peoples’ Republic of Bangladesh, Dhaka, 2011.

[2] BFFEA, "Basic Information'S on Frozen Food Industry in Bangladesh," Shrimp and Fish News, Newsletter of Bangladesh Frozen Foods Exporter's Association, Dhaka, 2006.

[3] B. R. Reddy and G. Finne, "Hydrolytic and Enzymatic Breakdown of Food Grade Condensed Phosphates in White Shrimp (Penaeus setiferus) Held at Different Temperatures," Proceedings of 11th Annual Tropical and Subtropical Fisheries Technical Conference of the Americas, Florida, 13-16 January 1986, pp. 201-212.

[4] A. H. Sutton, "Polyphosphate Treatment of Cod Muscle," In: R. Kreuzer, Ed., Freezing and Irradiation of Fish, Fishing News Books Ltd., London, 1969, pp. 172-178.
[5] R. J. Krause, H. W. Ockerman, B. Krol, P. C. Moerman and R. F. Plimpton Jr., "Influence of Tumbling, Tumbling Time, Trim and Sodium Tripolyphosphate on Quality and Yield of Cured Hams,” Journal of Food Science, Vol. 43, No. 3, 2006, pp. 853-855. doi:10.1111/j.1365-2621.1978.tb02438.x

[6] P. Howgate, A. Johnston and K. J. Whittle, "Multilingual Guide to EC Freshness Grades for Fishery Products,” Torry Research Station, Food Safety Directorate, Ministry of Agriculture, Fisheries and Food, Aberdeen, 1992.

[7] V. Tenhet, G. Finne, R. Nickelson and D. Toloday, "Penetration of Sodium Tripolyphosphate into Fresh and Prefrozen Peeled and Deveined Shrimp," Journal of Food Science, Vol. 46, No. 2, 1981, pp. 344-349. doi:10.1111/j.1365-2621.1981.tb04858.x

[8] A. Goncalves and J. L. D. Ribeiro, "Optimization of the Freezing Process of Red Shrimp (Pleoticus muelleri) Previously Treated with Phosphates,” International Journal of Refigeration, Vol. 31, No. 7, 2008, pp. 1134-1144. doi:10.1016/j.ijrefrig.2008.03.005 